\title{
The Psychometric Properties of the Post-Traumatic Stress Disorder Symptom Scale-Interview Based on DSM-5, in Military Personnel Participated in Warfare
}

\section{ART ICLE INF O}

\section{Article Type}

Descriptive Study

\section{Authors}

Karimi M. ${ }^{1} M S c$,

Rahnejat A.M. ${ }^{* 1} P h D$,

Dabaghi P. ${ }^{1} P h D$

Taghva A. ${ }^{2} M D$

Majdian M. ${ }^{3} \mathrm{PhD}$,

Donyavi V. ${ }^{2} M D$,

Shahed-HaghGhadam H. ${ }^{4} M S c$

How to cite this article
Karimi M, Rahnejat A.M, Dabaghi
P, Taghva A, Majdian M, Donyavi
V, Shahed-HaghGhadam H. The
Psychometric Properties of the
Post-Traumatic Stress Disorder
Symptom Scale-Interview Based
on DSM-5, in Military Personnel
Participated in Warfare. Iranian
Journal of War \& Public Health.
2020;12(2):115-124.

${ }^{1}$ Department of Clinical Psychology, Medicine Faculty, Aja University of Medical Sciences, Tehran, Iran ${ }^{2}$ Psychiatry Department, Medicine Faculty, Aja University of Medical Sciences, Tehran, Iran

${ }^{3}$ Behavioral Sciences Research Center, Baqiyatallah University of Medical Sciences, Tehran, Iran

${ }^{4}$ Clinical Psychology Department, Varamin Branch, Islamic Azad University, Varamin, Iran

\section{*Correspondence}

Address: Department of Clinical Psychology, Psychiatric Hospital of the Islamic Republic of Iran Army Ground Forces, Oshan Blvd., Artesh Hwy., Tehran, Iran.

Phone: +98 (21) 22195164

Fax: +98 (21) 22197198

arahnedjat@yahoo.com

\section{Article History}

Received: January 21, 2020

Accepted: May 19, 2020

ePublished: June 17, 2020

\section{A B S T R A C T}

Aims This study aimed to investigate the psychometric properties of the Post-Traumatic Stress Disorder (PTSD) symptom scale-interview for DSM-5 (PSS-I-5) in military personnel involved in warfare.

Instruments \& Methods This was a validation study. A descriptive research method was used. The participants in this study consisted of 287 veterans with PTSD who referred to (505 Army Psychiatric Hospital) selected using the availability sampling method. The instruments used in this study included the PSS-I-5 scale as the main research tools, Beck Depression Inventory-II (BDI-II) and State-Trait Anxiety Inventory (STAI) assessed the convergent validity, and PTSD Checklist for DSM-5 (PCL-M-5) and Clinician-Administered PTSD Scale for DSM-5 (CAPS-5) were also used to measure simultaneous validity. The data were analyzed using the correlation coefficient and the Cronbach's alpha methods.

Findings The results demonstrated that Cronbach's alpha of the PSS-I-5 scale was at a desirable level ( $\alpha=0.91)$. PSS-I-5 had good convergent and divergent validity. The sensitivity of PSS-I-5 was equal to $0.97 \%$, and its specificity was obtained to be $0.62 \%$. Further, the analysis of the results revealed that PSS-I-5 could differentiate between sick and healthy individuals.

Conclusion The PSS-I-5 scale has desirable reliability and validity for military personnel participating in the war and can be used to identify and screen military personnel involved in warfare and military missions.

Keywords PTSD; Psychometric; Reliability; Validity; DSM-5

\section{I T A T I O N L I N K S}

[1] Combat trauma: Treatment from ... [2] A systematic review and meta ... [3] Lifetime traumatic experiences and their impact ... [4] Potentially traumatic event exposure, posttraumatic ... [5] Intrusive traumatic recollections and ... [6] Determinants of the development... [7] Trauma exposure and post-traumatic ... [8] Prevalence of post-traumatic stress ... [9] Diagnostic and statistical manual ... [10] Prevalence of post-traumatic stress ... [11] Predictors of posttraumatic ... [12] Posttraumatic stress disorder ... [13] Size and burden of mental ... [14] Prevalence, severity, and comorbidity ... [15] Prevalence of mental disorders in Europe ... [16] Disability and quality of life impact ... [17] 12-month comorbidity patterns ... [18] Understanding sequelae of injury ... [19] Posttraumatic stress disorder in ... [20] Post-traumatic stress disorder by ... [21] Psychological burden of PTSD ... [22] Weekly changes in blame and PTSD ... [23] Trauma and the Vietnam War ... [24] Population attributable fractions ... [25] Combat duty in Iraq and Afghanistan ... [26] Trends and risk factors for mental ... [27] Invisible wounds of war ... [28] PTSD symptom increases in Iraq ... [29] Delayed-onset posttraumatic stress ... [30] Correlates of posttraumatic stress ... [31] Reliability and validity of a brief instrument ... [32] The meta-analysis of the effectiveness ... [33] Psychometric properties ... [34] Validity and reliability of Persian version ... [35] Comparison of Beck Depression ... [36] Meaning assignment structures ... [37] Comparing of alexithymia, defensive ... [38] The prevalence of post-traumatic ... [39] Psychometric properties of ... [40] Impact of peer support on PTSD, hope ... [41] Post-traumatic stress in asylum seekers ... [42] Posttraumatic stress disorder in ... [43] Normalization of clinician administered ... [44] An acceptance and commitment ... [45] Music therapy to regulate arousal and ... [46] The Clinician-Administered PTSD ... [47] The posttraumatic stress disorder ... [48] Psychometric analysis of the PTSD ... [49] Reliability and validity of severity ... [50] Clinical validity and intrarater and ... [51] Psychometric properties of the Arabic ... 


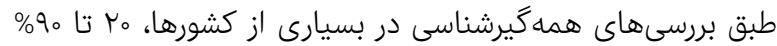

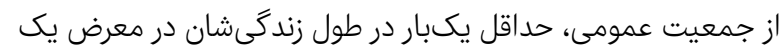

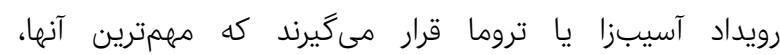

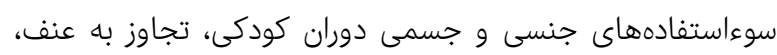

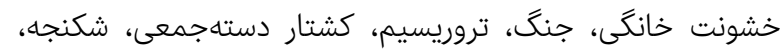

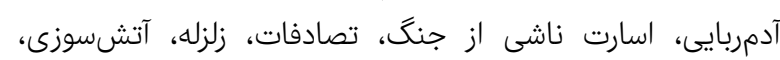

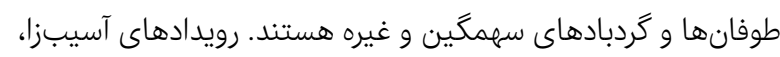
شامل حملهها و تجاوزهايى به سيستم ذهنى و بدنى انسان هستند كه خردهسيستمهاى متعددى را تحت تاثير خودشان قرار مىدهن دهند

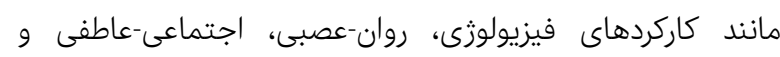

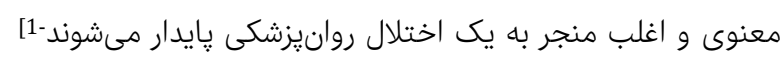

در اين راستا يكى از اختلالات روانشناختى كه ارتباط معنادارى در

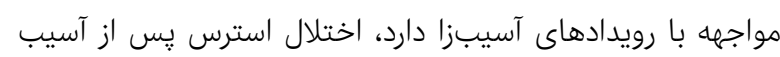
(Post-Traumatic Stress Disorder; PTSD) كه نتايج برخى از مطالعات مانند راهنجات و همكاران[8] حاكى از

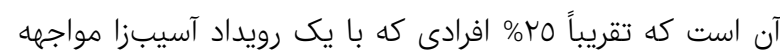

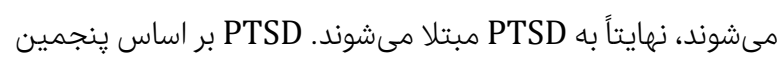

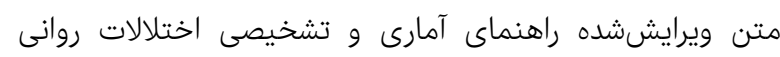
(Diagnostic and Statistical Manual of Mental Disorders, 5th Edition; DSM-5) مستمر و مكرر است كه يس از تجربه يا مشاهده يك رويداد آسيبزا

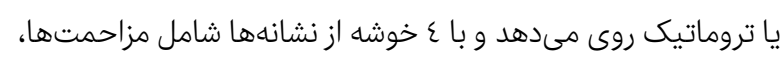

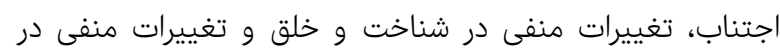

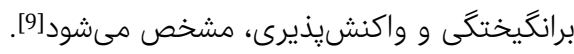

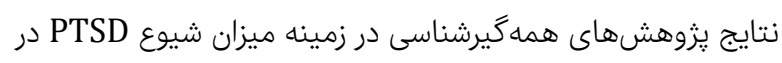

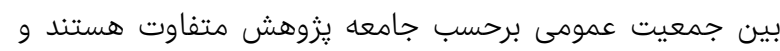

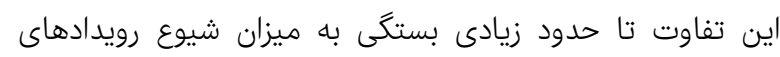

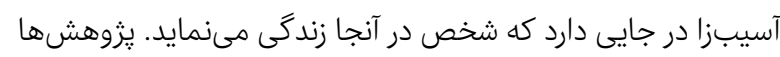

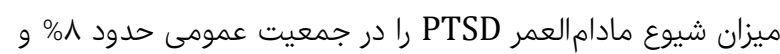

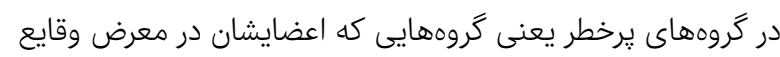

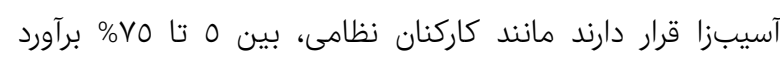

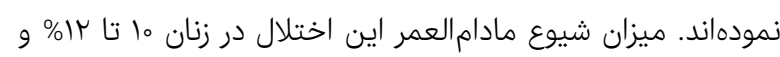

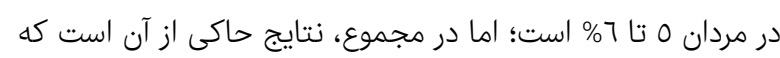

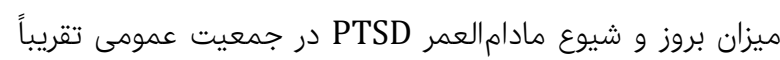

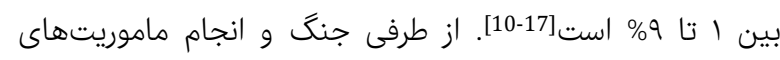

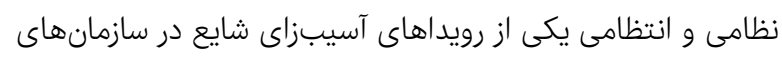

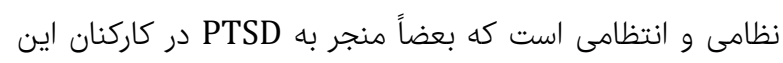

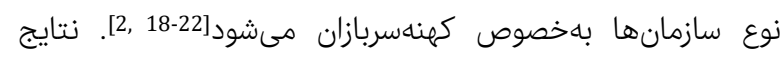

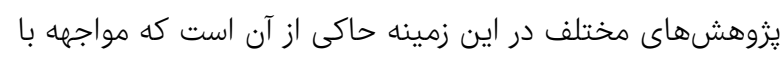

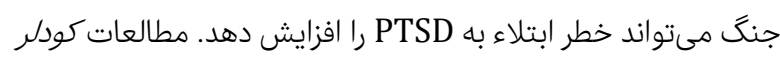

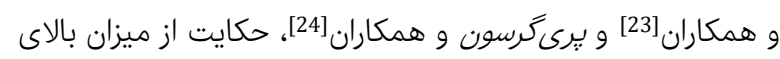

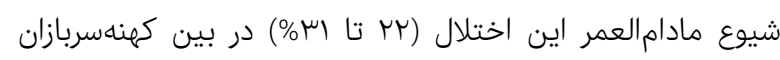

ويزگىهاى روانسنجى مقياس/مصاحبه علايم

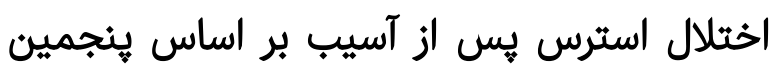
نسخه راهنماى آمارى و تشخيص اختلالات روانى در نظاميان شركت رننده در جنگ و اهنى

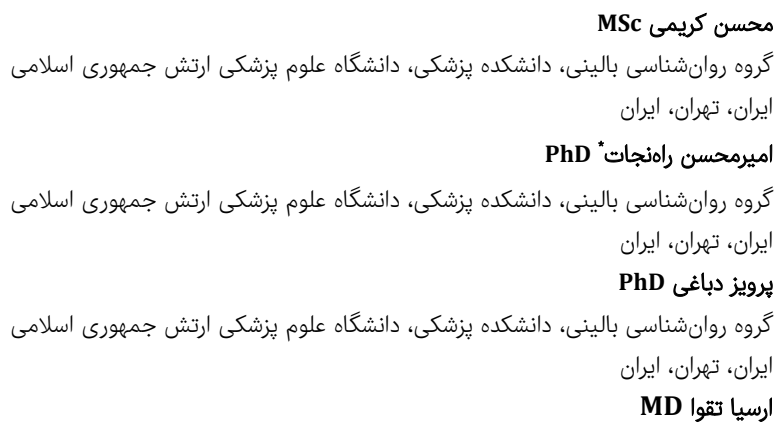

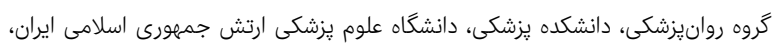
تهران، ايران

PhD محمد مجديان

مركز تحقيقات علوم رفتارى، دانشكاه علوم يزشكى بقيه الله (عج)، تهران، ايران

MD وحيد دنيوى تحقيقات علوم رون

كَروه روانيزشكى، دانشكده يزشكى، دانشگًاه علوم يزشكى ارتش جمهورى اسلامى ايران، تهران، ايران

هاله شاهد حققدم تهرن ايرن

گروه روانشناسى بالينى، واحد ورامين، دانشگاه آزاد اسلامى، ورامين، ايران

جكيده

هدف: اين يزوهش با هدف بررسى ويزگىهاى روانسنجى مقياس علايم اختلال

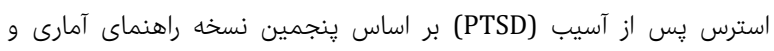
تشخيص اختلالات روانى (PSS-I-5) در نظاميان شركتكننده در جنگ انج انجام

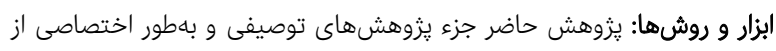

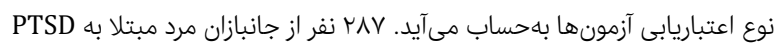
مراجعهكننده به بيمارستان فوق تخصصى روانيزشكى

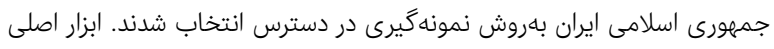

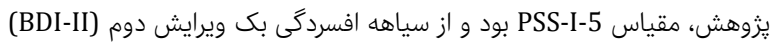
و مقياس اضطراب حالت-صفت (STAI) بهمنظور سنجش روايى واگرا و از فهرست نشانههاى اختلال استرس يس از آسيب (PCL-M-5) و مقياس اجرايى بالينى إنى

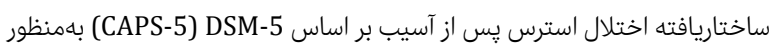

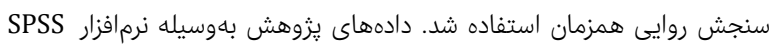

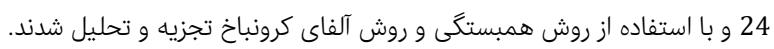

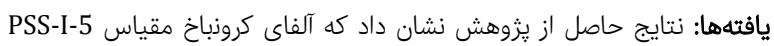

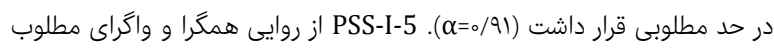

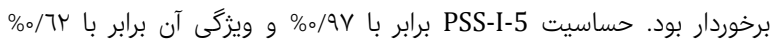

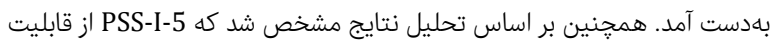
افتراق بين افراد بيمار و سالم برخوردار است. نتيجه

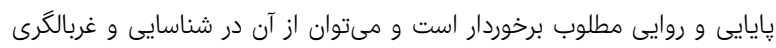

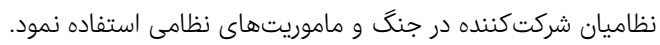

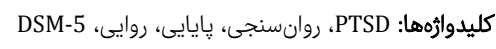

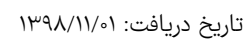

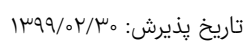
نويسنده مسئول: arahnedjat@yahoo.com 
ويثرىهاى روانسنجى مقياس/مصاحبه علايم اختلال استرس يس از آسيب بر اساس ...

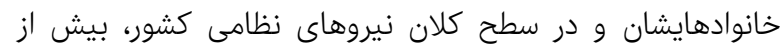

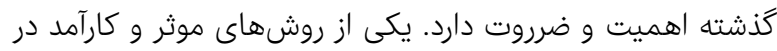

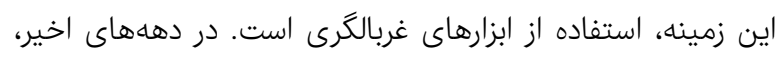

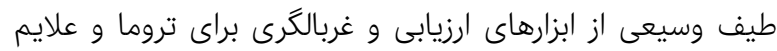

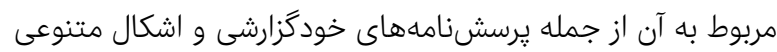

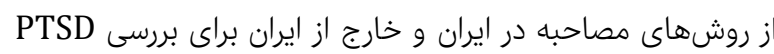

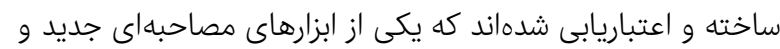

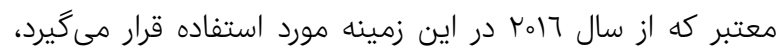

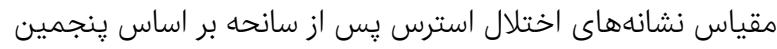

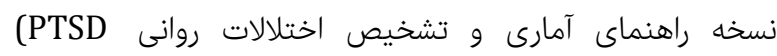
Symptom Scale-Interview for DSM-5; PSS-I-5) جكليست PSS-I-5 بر اساس DSM-5 طراحى شده و يك مقياس

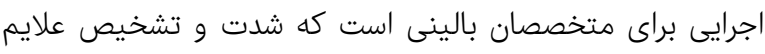

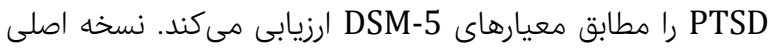

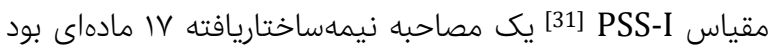

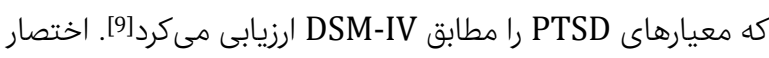

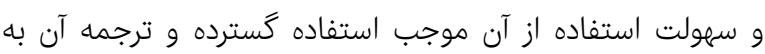

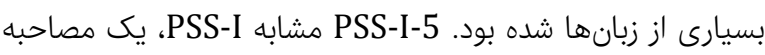
نيماساختاريافته انعطافيذير است كه بهان به متخصصان بان بالينى، اجازه

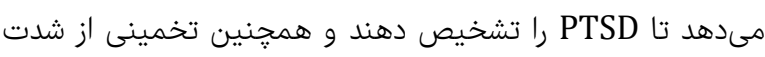

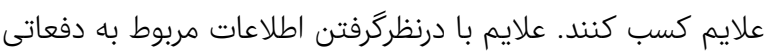

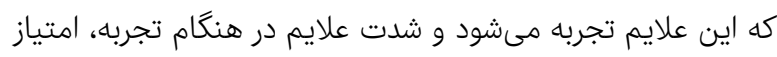

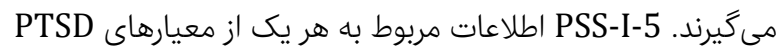

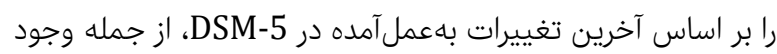

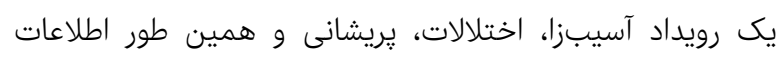

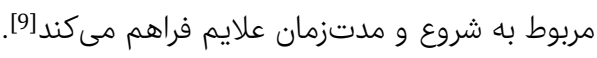

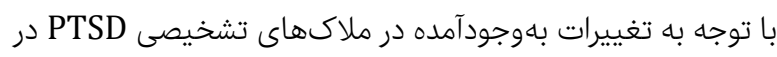

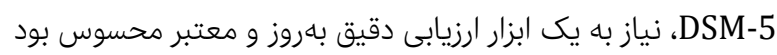

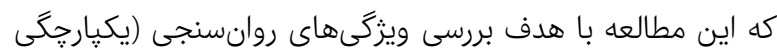

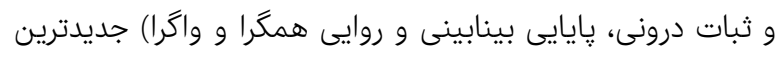

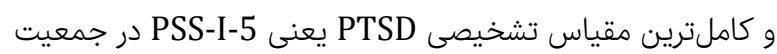

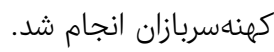

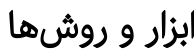

يزوهش حاضر از نظر هدف، كاربردى، از حيث كَردآورى اطلاعات،

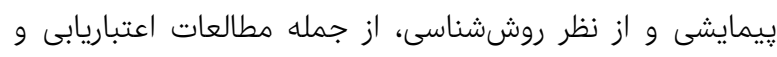

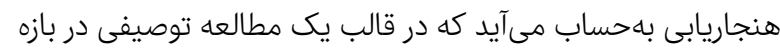

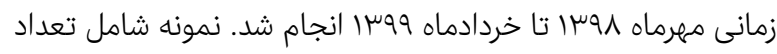

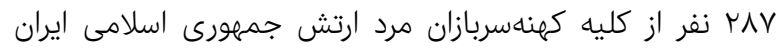

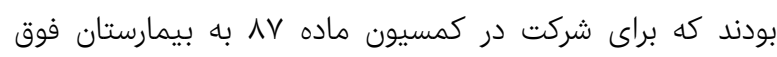

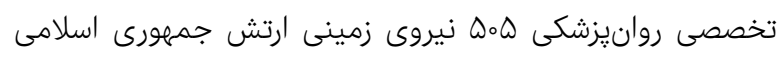

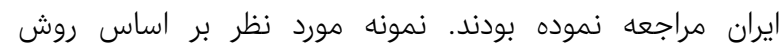

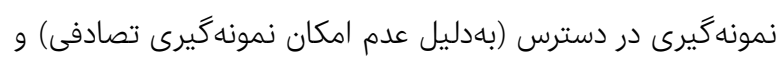

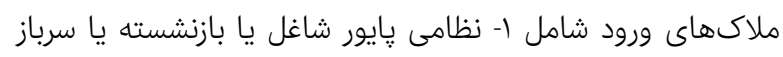

دارند. در مطالعات هوك و همكاران[25]، سيل و همكاران[26]،

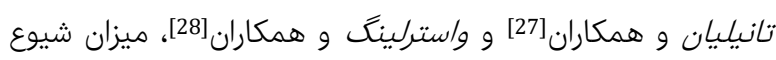

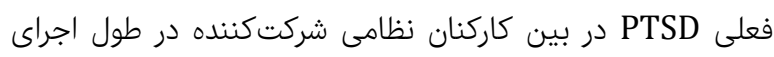

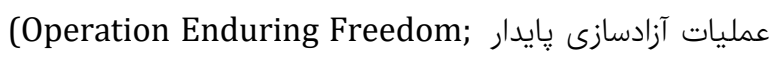

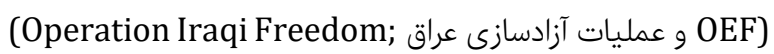

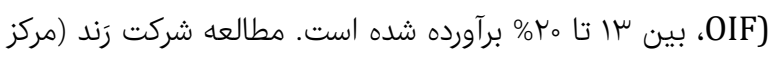
تحقيقات تعيين سياستهاى بهداشتى در نيروهاى نظامى ارتش

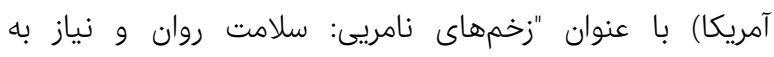

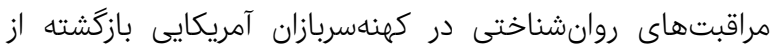

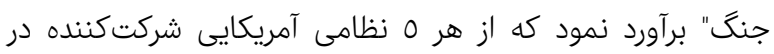

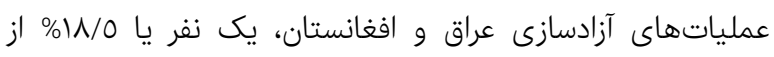

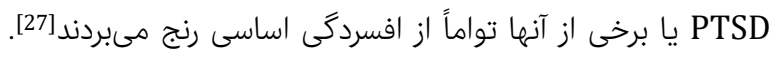

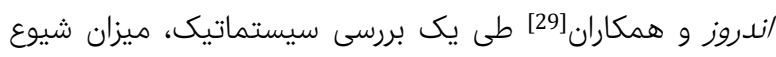

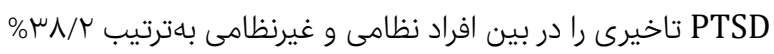

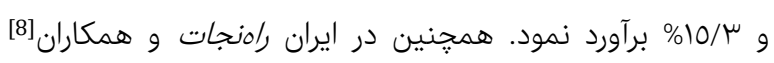
ميزان شيوع PTSD را در كهنهسربازان ارتش جمهورى اسلامى ايران، ع ع ع برآورد نمودند.

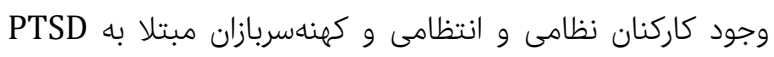

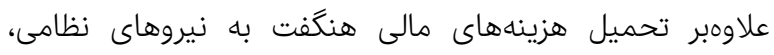

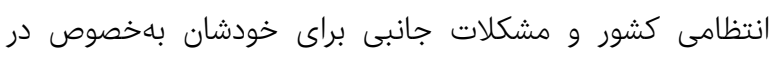

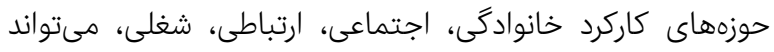

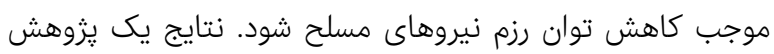

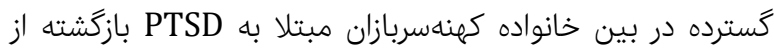

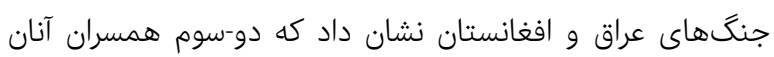

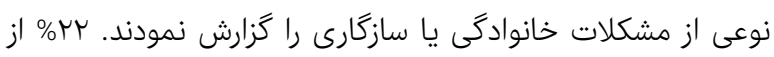

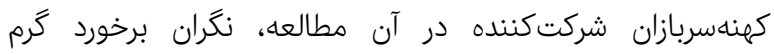

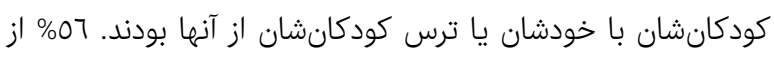

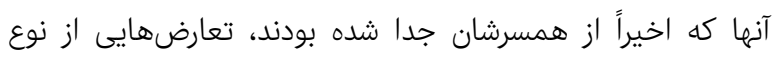

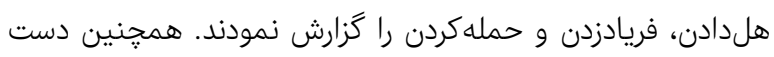

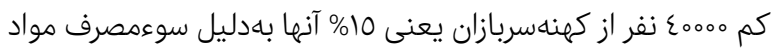

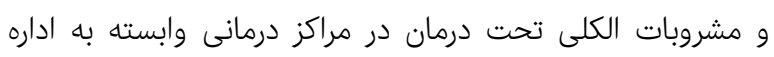

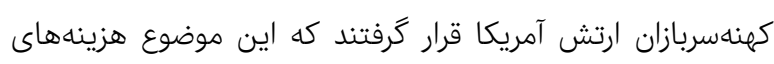

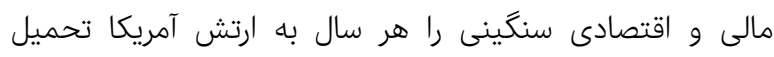

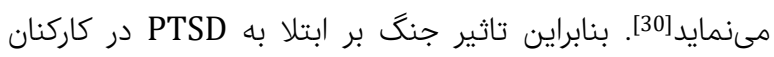

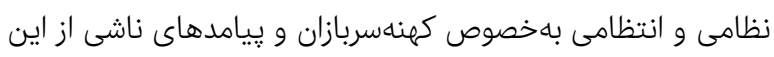

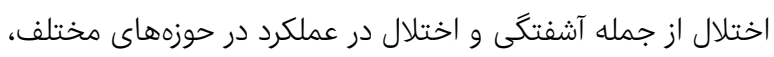

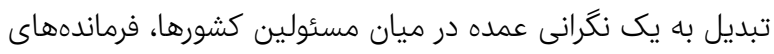

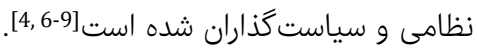

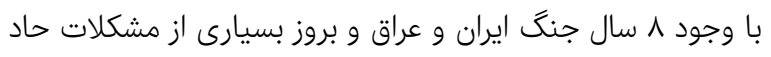

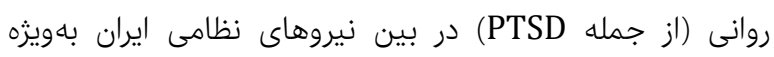

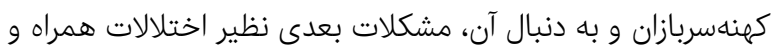

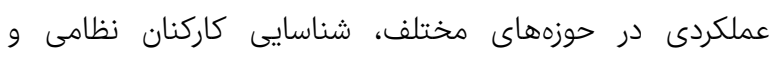

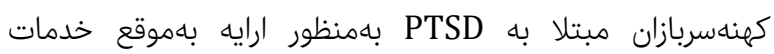

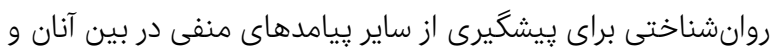


داراى روايى همكرا با س مقياس اجرايى بالينى ساختاريافته اختلال

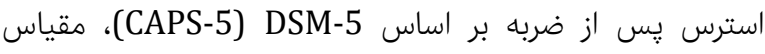

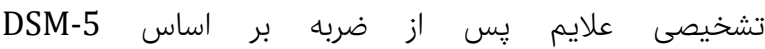
Posttraumatic Diagnostic Scale for DSM-5) مخصوص קكليست PTSD Checklist-Specific PTSD (Beck بوده و با سياهه افسردكى بك ويرايش دوم Version) Depression Inventory-II; BDI-II) حالت-صفت State-Trait Anxiety Inventory; STAI) داراى روايى واكرا بود. تجزيه و تحليل ويزَّىهاى مهم اين مقياس، نمره

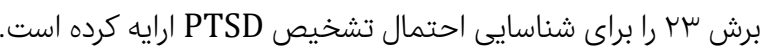

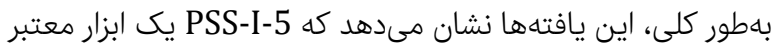

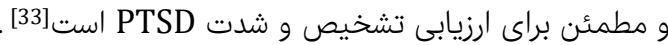

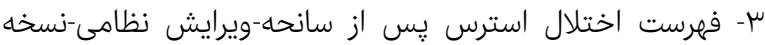

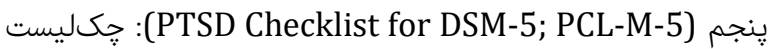
يك مقياس خودگزارشدهى است كه براى ارزيابى PCL-M-5

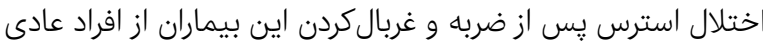

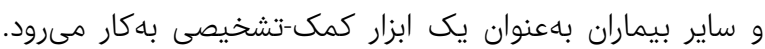

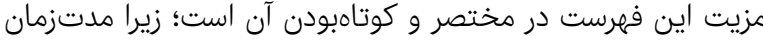

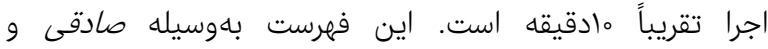

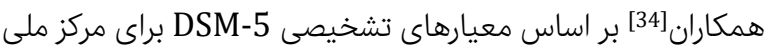

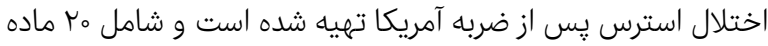

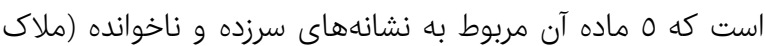

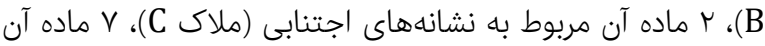

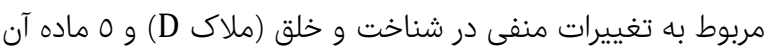

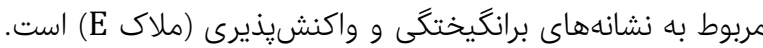

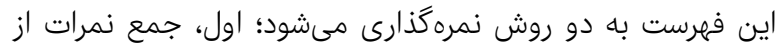

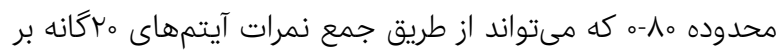

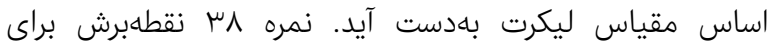

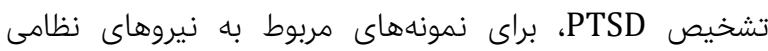

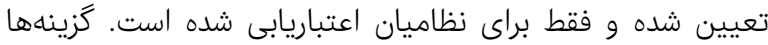

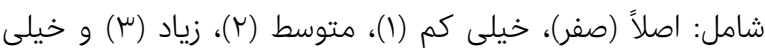

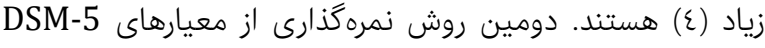

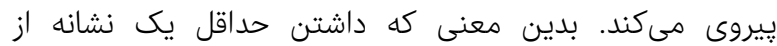

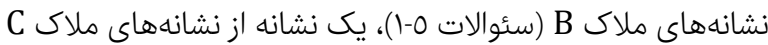

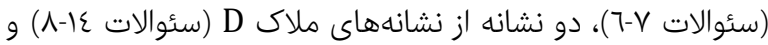

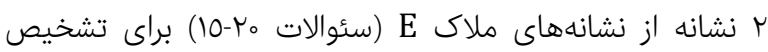

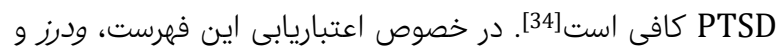

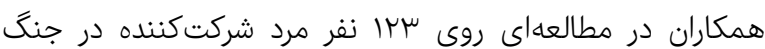

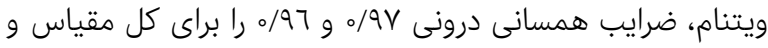

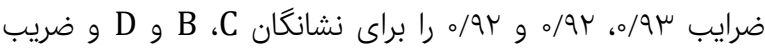

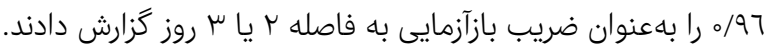

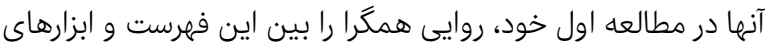

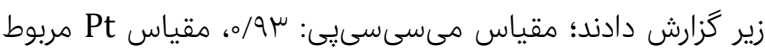

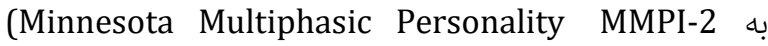

منقضى خدمت در يكى از نيروهاى جهاركانها ارتش (نيروى يدافند،

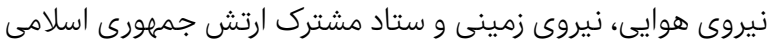

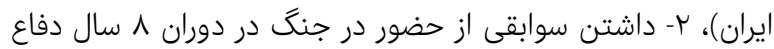

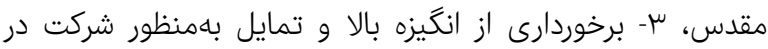

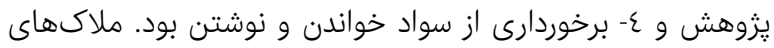

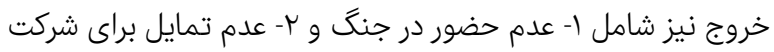

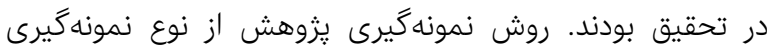

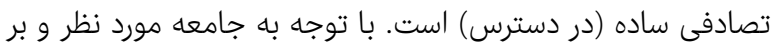

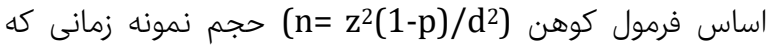

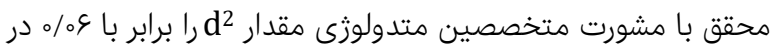

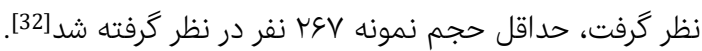
در يزوهش حاضر از ابزارهاى ذيل استفاده شد:

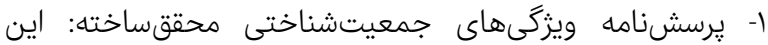
يرسشنامه حاوى يرسش وهايى بود كه بهمنظور جمعآورى اطلاعات

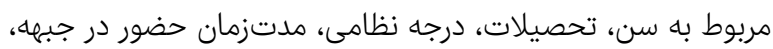

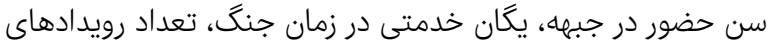

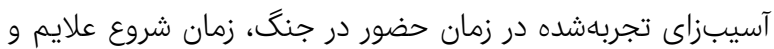

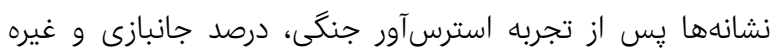

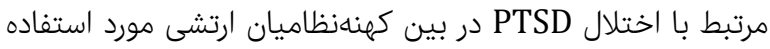

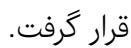
r- مقياس علايم اختلال استرس يُ إس از آسيب بر اساس ينجمين نسخه راهنماى آمارى و تشخيص اختيلاسلالات روانى (PSS-I-5): جكليست PSS-I-5 بهعنوان يك مصاحبه نيمانساختاريافته

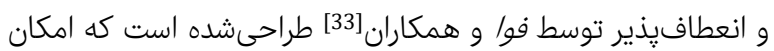
تشخيص PTSD و همجنين امكان رسيدن به يك ارزيابى از شدت

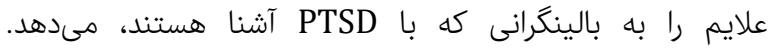

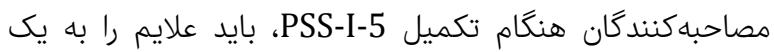

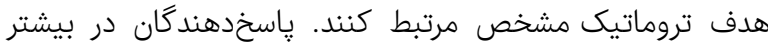

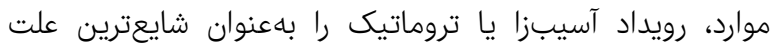

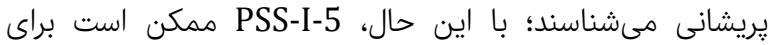

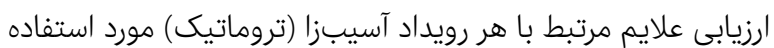

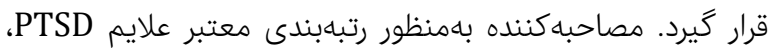

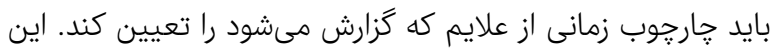

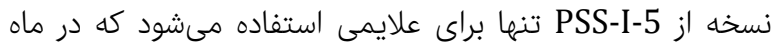
كذشته اتفاق افتادهاند. بهصورت نظرى، ارزيابى علايم در طول دورههاى زمانى طولانىتر و كوتاهتر هم استفاده شود، اما روايى مصاحبه در اين شرايط مورد بررسى قرائ قرار

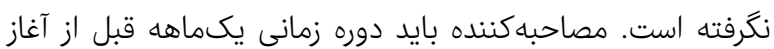

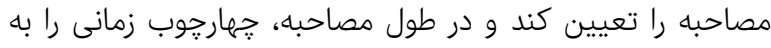

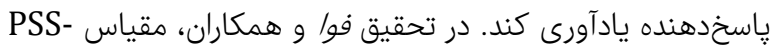

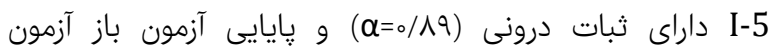

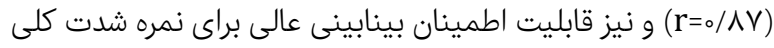

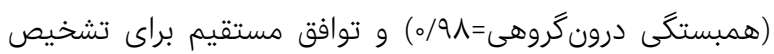

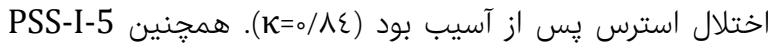


ويزگىهاى روانسنجى مقياس/مصاحبه علايم اختلال استرس بس از آسيب بر اساس ... 119

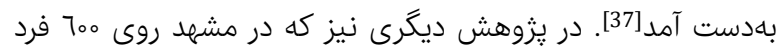

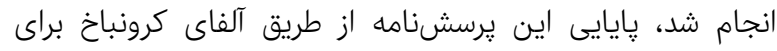

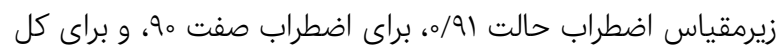

مقياس عq/ه بهدست آمد [37]. 7- مقياس اجرايى بالينى ساختاريافته اختلال استرس يس إس از ضربه

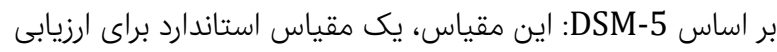

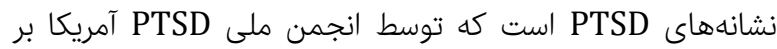

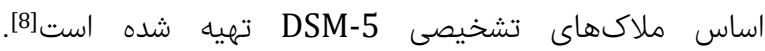

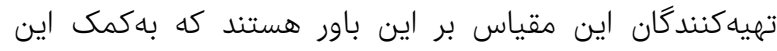

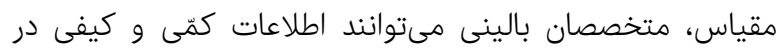
زمينه نشانههاى PTSD بهدست آورند. اين مقياس براى هرائن هر علامت

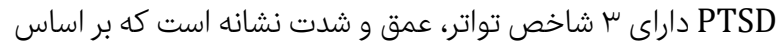
تعريف، شدت نشانه عبارت از مجموع نمره فراوانى و عمق اثر هر

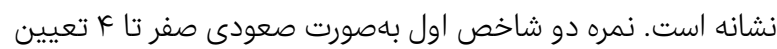

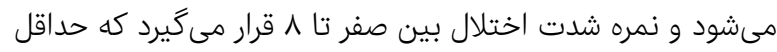

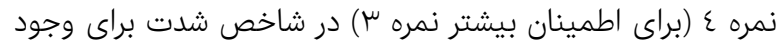

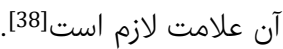

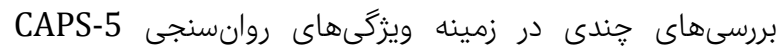
انجام شده است كه (Clinician-Administered PTSD Scale) گوياى پايايى و روايى بالاى اين مقياس است. بلانجارد و و

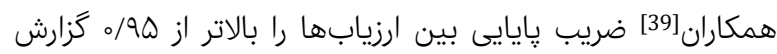

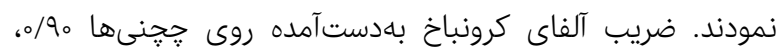

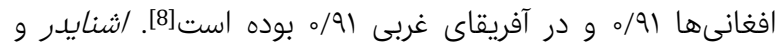

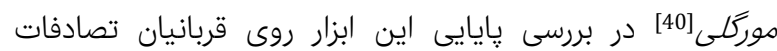

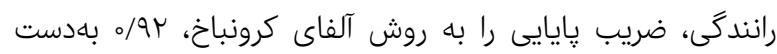
آوردند. رننر و همكاران [41] اين مقياس راس را در مقايسه بائ رونس ساير ابزارهاى سنجش علايم PTSD داراى بيشترين ضريب تشخيص دانستهاند. مقياس مذكور از طريق اداره كهنهسربازان ايالاتمتحده آمريكا

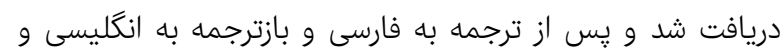

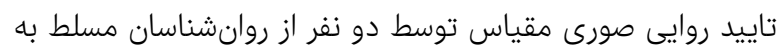

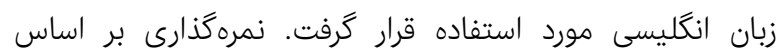
دستورالعمل اجرايى مقياس بهصورت مصاحبه ساختاريافته مبنى بر برد

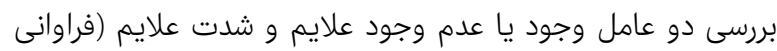

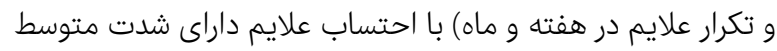

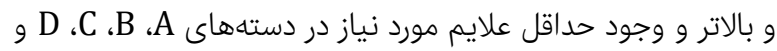
E براى تشخيص اختلال و علايم هر دسته از اختلالات بر مبناى

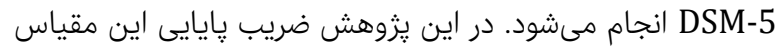

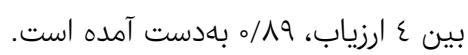

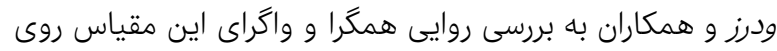

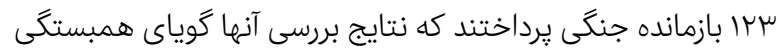

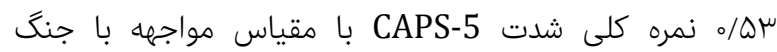
(Combat Exposure Scale; CES)

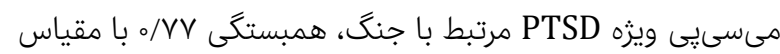

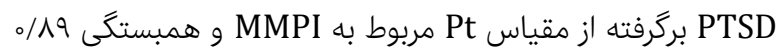

\%/VV :Inventory-2) مقياس اثر حادثه: /ه، مقياس رويارويى

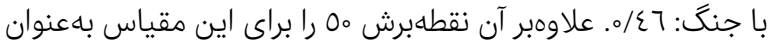
نقطه بهينه براى بيشبينى تشخيصهاه علای

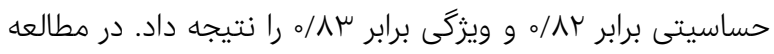

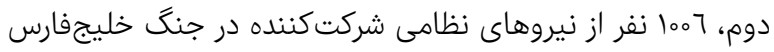

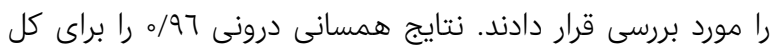

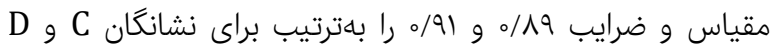

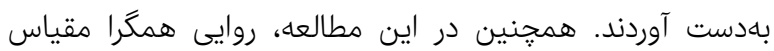

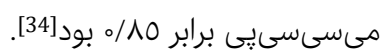

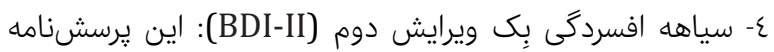

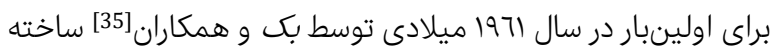

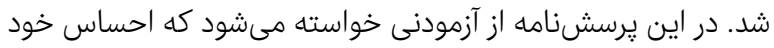

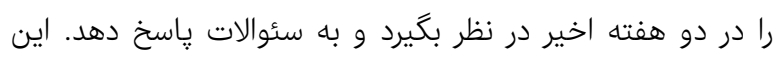
يرسشنامه براى سنجش شدت افسردگى در بزرگسالان و نوجوانان

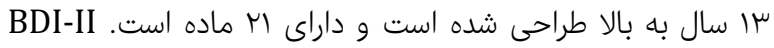
داراى اب گَويه است و هر گويه متشكل از ع جمله است كه فرد بايد

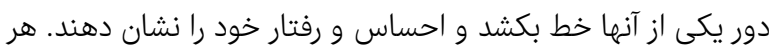

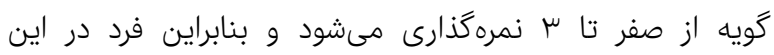
يرسشنامه مىتواند نمرهاى بين صفر تا سج كسب كند [35]. بهمنظور

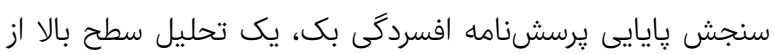

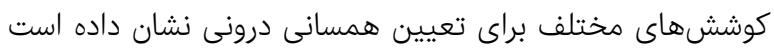

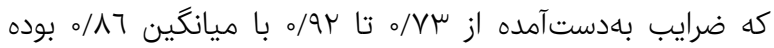

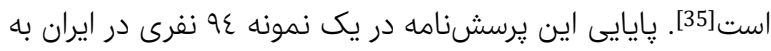

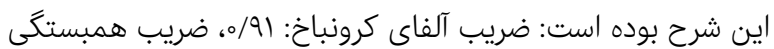

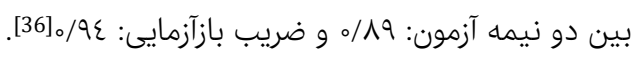

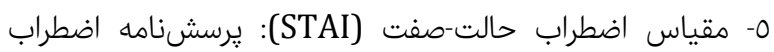

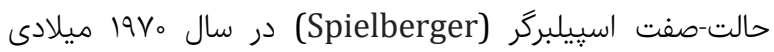

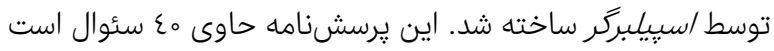

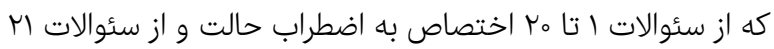

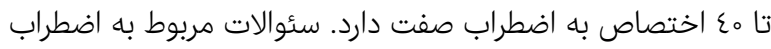

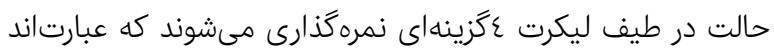

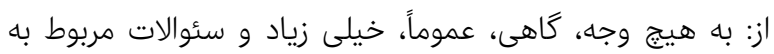

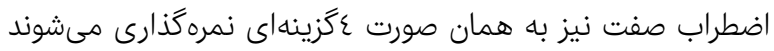

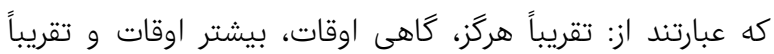

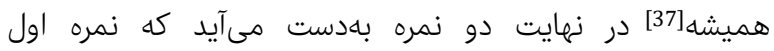

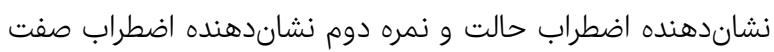

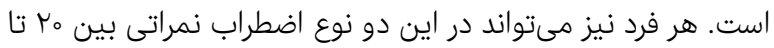

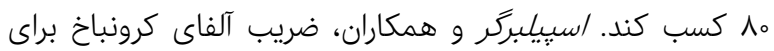

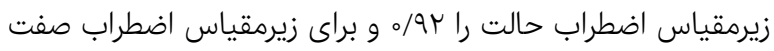

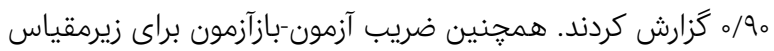

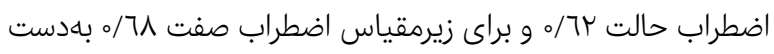

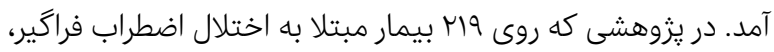

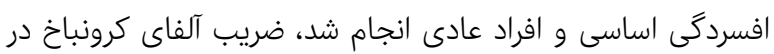

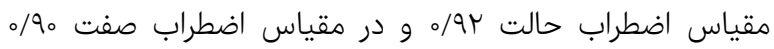


ميانكين سن مشاركت كنندكان در زمان جنگ

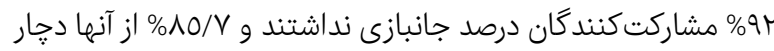

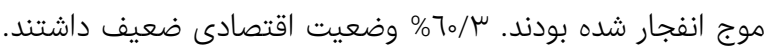

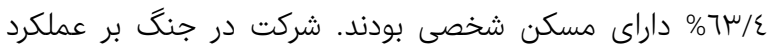

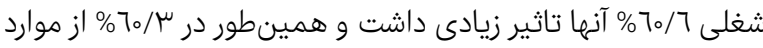

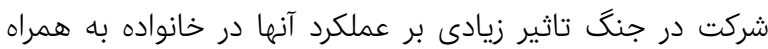

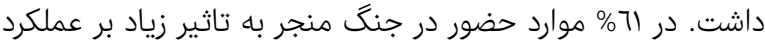

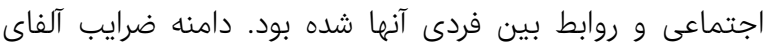

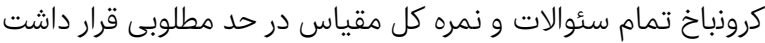

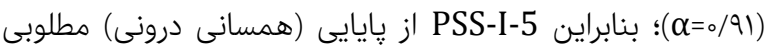

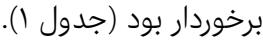

جدول () نتايج پايايى يرسشهاى مقياس PSS-I-5 جرسياس

\begin{tabular}{|c|c|c|}
\hline ضرايب آلفاى كرونباخ & ميانكين آمارى & شماره يرسش \\
\hline ०/११६ & $r / \circ \kappa_{ \pm} / \wedge l$ & PSSI1 \\
\hline.$/ 910$ & 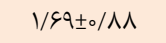 & PSSI2 \\
\hline o/914 & $1 / \mu_{ \pm}{ }_{ \pm 0} / V \varepsilon$ & PSSI3 \\
\hline.$/ 914$ & 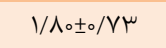 & PSSI4 \\
\hline.$/ 914$ & 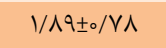 & PSSI5 \\
\hline.$/ 910$ & $1 / \varphi_{ \pm} \pm / q \Lambda$ & PSSI6 \\
\hline.$/ 911$ & $1 / \& V \pm I / \circ \mu$ & PSSI7 \\
\hline.$/ 919$ & $1 / 11 \pm 0 / 9$ 。 & PSSI8 \\
\hline ـ/91\% & 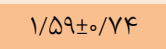 & PSSI9 \\
\hline ०/919 & 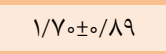 & PSSI10 \\
\hline.$/ 910$ & $V / \wedge \mu_{ \pm 0} / V k$ & PSSI11 \\
\hline ./9/F & $1 / \mathrm{V} \pm \pm_{0} / V^{\mu}$ & PSSI12 \\
\hline.$/ 910$ & V/A $\mu_{ \pm 0} / \wedge \vee$ & PSSI13 \\
\hline ०/919 & $1 / \& K_{ \pm} / V \Delta$ & PSSI14 \\
\hline.$/ 911$ & r/QR土o/VV & PSSI15 \\
\hline o/9MI & 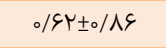 & PSSI16 \\
\hline.$/ 910$ & $r / Y K \pm 0 / A r$ & PSSI17 \\
\hline.$/ 91 k$ & $r / N F_{ \pm} / V K$ & PSSI18 \\
\hline ./9/F & 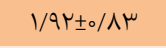 & PSSI19 \\
\hline.$/ 910$ & $r / \Lambda \Delta \pm 0 / \wedge \varepsilon$ & PSSI20 \\
\hline 191. & $\kappa r / \mu \omega \pm\left.\right|_{0} / \wedge \varepsilon$ & نمره كل \\
\hline
\end{tabular}

براى بررسى روايى همكراى PSS-I-5، از ضريب همبستخى ييرسون

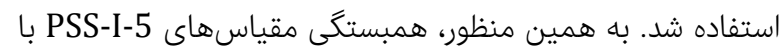

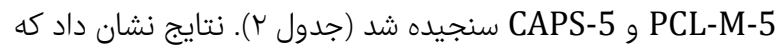

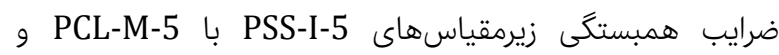

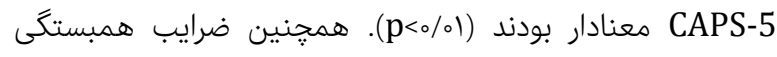

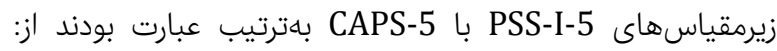

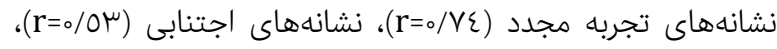

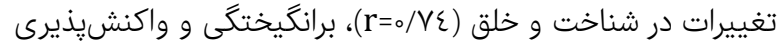

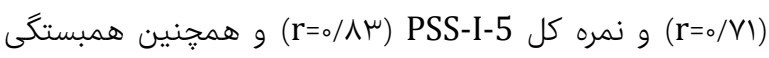

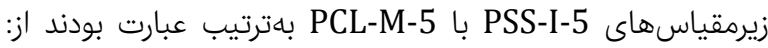

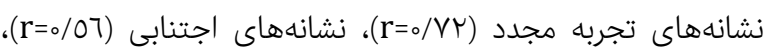

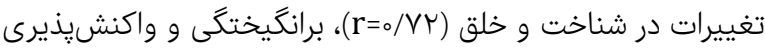

با شمار علايم PTSD در مصاحبه بالينى ساختاريافته براى

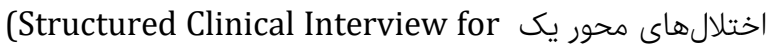
DSM Disorders; SICD)

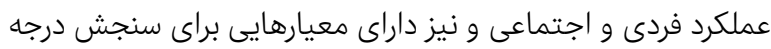

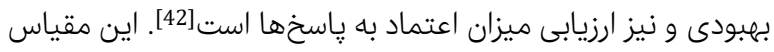

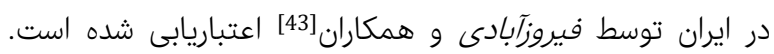

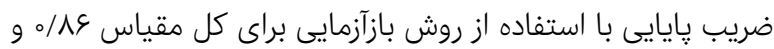

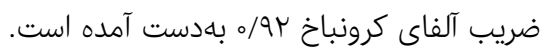

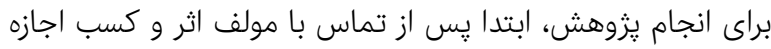

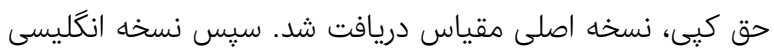

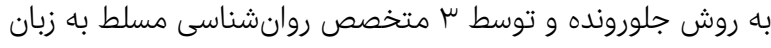

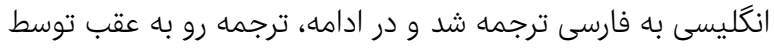

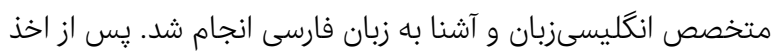
مجوزهاى لازم (به شماره: يرسشنامههاى آمادهشه در اختيار مشاركتكنندكان قرار گرفتت.

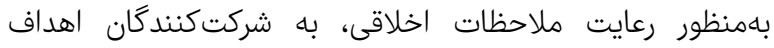

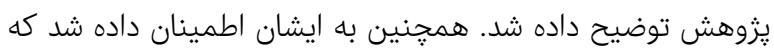

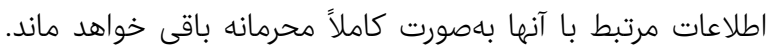

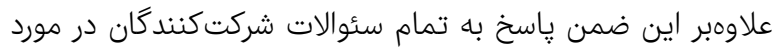

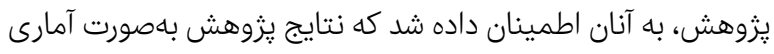

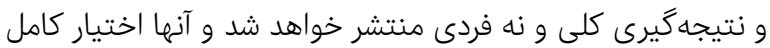

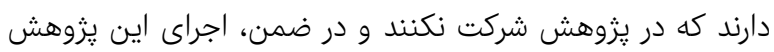

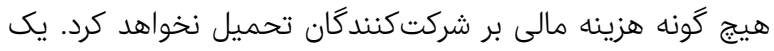

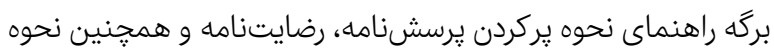

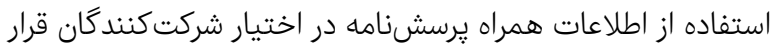

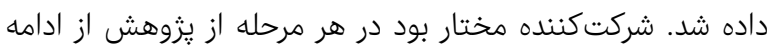

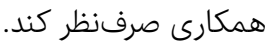
ويزگكىهاى روانسنجى PSS-I-5 از طريق محاسبه روايى (سازه و

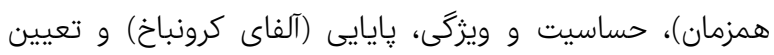

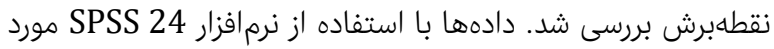
تجزيه و تحليل قرار كَرفتند.

\section{يافتهها}

r برا نفر از مشاركتكنندكان بإيينتر از 00 سال و 170 نفر بالاتر از

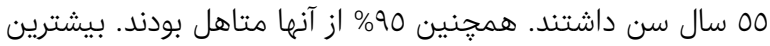

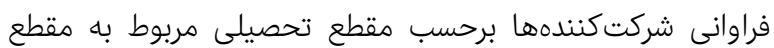

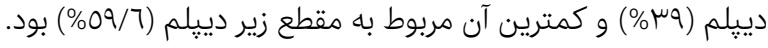

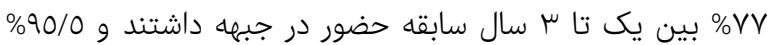

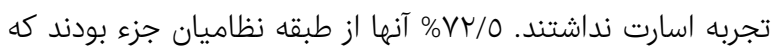

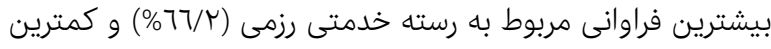

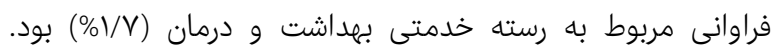

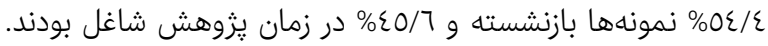

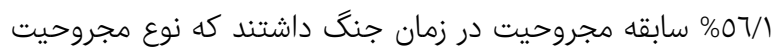
در 70/7\% اين افراد هم مجروحيت جسمى و هم موج انفجار بود. 
ويزگىىهاى روانسنجى مقياس/مصاحبه علايم اختلال استرس يس از آسيب بر اساس ... آII

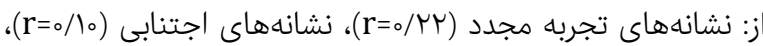
تغييرات در شناخت و خلق (Tr=or)، برانگيختخى و واكنشيذيرى

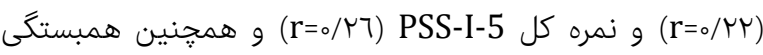
زيرمقياسهاى PSS-I-5 با BDI-II بهترتيب عبارت بودند از:

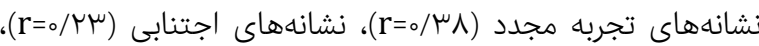

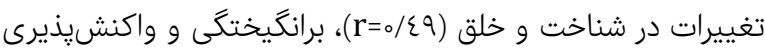
و نمره كل r=o/عq) ضرايب همبستگى زيرمقياسهاى PSS-I-5 با BDI-II و STAI، مىتوان گفت كه مقياس PSS-I-5 از روايى واگرا برخوردار بود. (r=o/70) PSS-I-5 از روايى همكرا برخوردار بود.

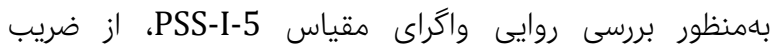

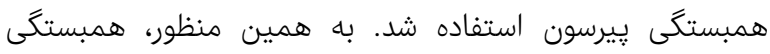

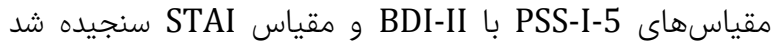

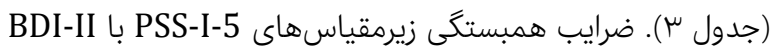

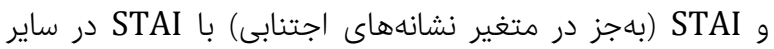

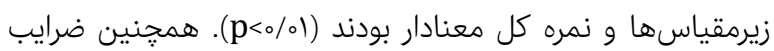

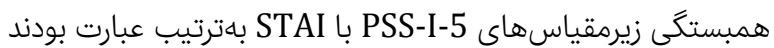

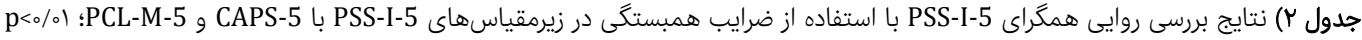

\begin{tabular}{|c|c|c|c|c|c|c|c|}
\hline نمره كل & واكنشيذيختىى و & شناخت و خلق & نشانههاى & نشانههاى تجريه & PCL-M-5 & CAPS-5 & متغيرها \\
\hline & & & & & & 1 & CAPS-5 \\
\hline & & & & & 1 & ०/19 & PCL-M-5 \\
\hline & & & & 1 & $\circ / V Y$ & $\circ / V K$ & نشانههاى تجربه مجدد \\
\hline & & & 1 & $\circ / Q 1$ & $\circ / Q S$ & /QU & نشانههاى اجتنابى \\
\hline & & 1 & $\circ / \omega_{\circ}$ & $\circ / V r$ & $\circ / V r$ & $\circ / V F$ & تغييرات در شناخت و خلق \\
\hline & 1 &.$/ 9 \Lambda$ & $0 / 41$ & o/q & $\circ / 9 \Delta$ & $\circ / \mathrm{VI}$ & برانكيختىى و واكنشيذيرى \\
\hline 1 & O/AK & $\circ / 91$ & ס/צ\& & O/AV & $\circ / \Lambda_{0}$ & 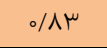 & نمره كل PSS-I-5 \\
\hline
\end{tabular}

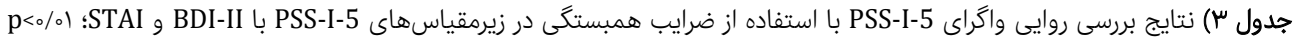

\begin{tabular}{|c|c|c|c|c|c|c|c|}
\hline نمره كل & برانكيختگى و & تغييرات در شناخت & نشانهاى اجنابى & تشربه مجدهاى & BDI-II & STAI & متغيرها \\
\hline & & & & & & 1 & STAI \\
\hline & & & & & 1 & $\circ / M K^{*}$ & BDI-II \\
\hline & & & & 1 & o/ &.$/ T r$ & نشانههاى تجربه مجدد \\
\hline & & & 1 & $\circ / \Delta 1$ & س & $\circ / 10$ & نشانههاى اجتنابى \\
\hline & & 1 & $\circ / \omega_{0}$ & $\circ / V Y$ & $0 / 49$ & 每 & تغييرات در شناخت و خلق \\
\hline & 1 & $0 / 9 \Lambda$ & $0 / 41$ & o/q & $0 / 4 q$ & $0 / r r$ & برانكيختىى و واكنشيذيرى \\
\hline 1 & o/Ak &.$/ 91$ & ०/9६ & ०/AV & $\circ / \Delta_{\circ}$ & ס/TE & PSS-I-5 نمره كل PSS \\
\hline
\end{tabular}

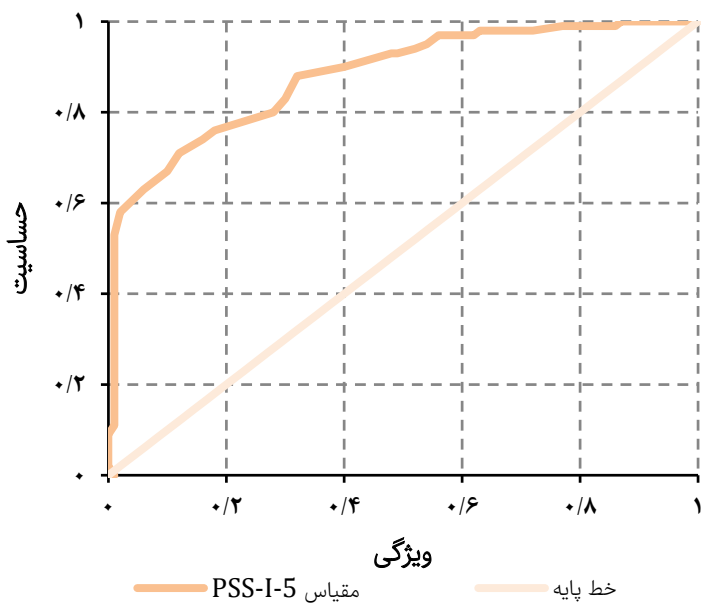

PSS-I-5 نمودار (1) منحنى راك مقياس
بهمنظور يافتن نقطهاى از نقطه نزديك تقارب كه بهترين حساسيت

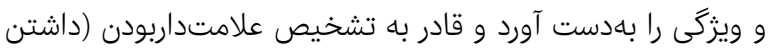

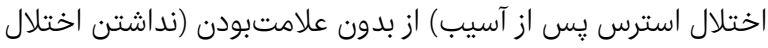

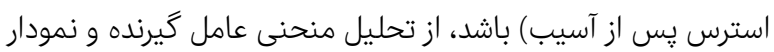

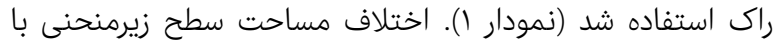
\%/A

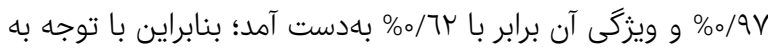

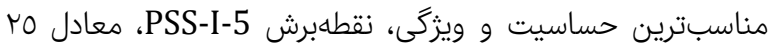

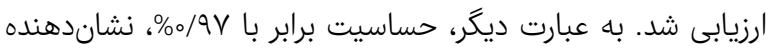
نمره بالاتر از ro (فرد علامتدار؛ اختلال استرس يس إس از آسيب) و و

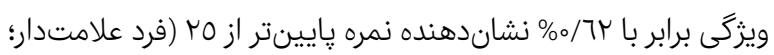
اختلال استرس يس از آسيب) بود (نمودار (). 
تشخيصى PTSD از اين مقياس استفاده نمود.

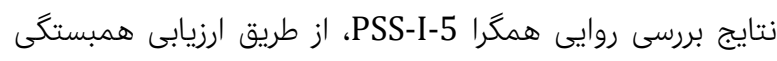

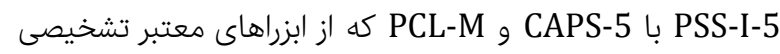

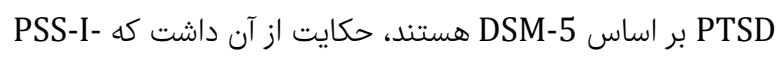
5 از روايى همگراى مناسب برخوردار بود. اين يافته نيز با نتايج

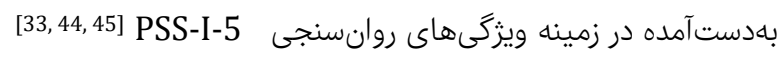

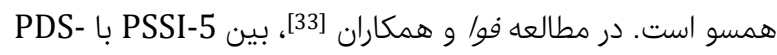

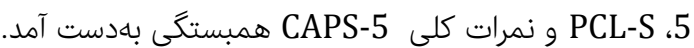

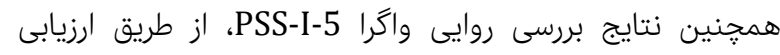

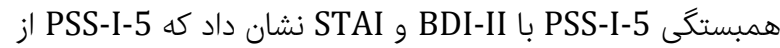
روايى واگراى مناسبى برخوردار بود. اين نتيجه با نتايج بررسىهاى

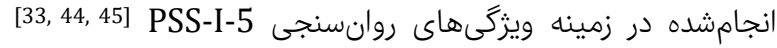

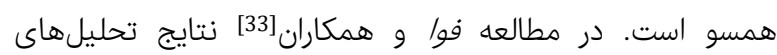
انجامشده نشان داد كه ارتباط بين PSSI-5 با STAI و

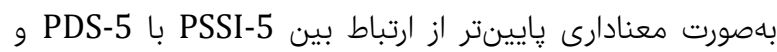

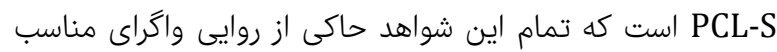
اين مقياس است. همجنين در اين مطالعه با توجه به نتايج تحليل منحنى راك،

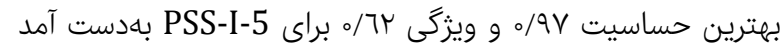

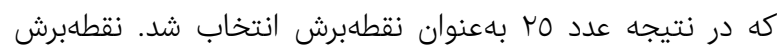

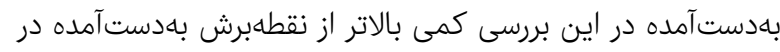

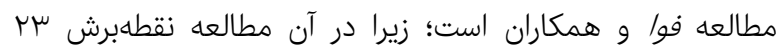

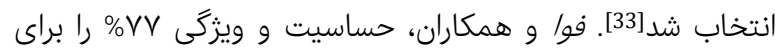
كSS-I-5

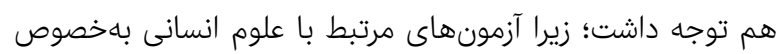

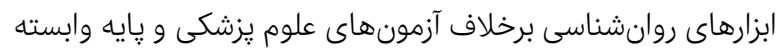
به فرهنگ هستند. از طرف ديگر جمعيت مورد مطالعه كهنهسربازانى

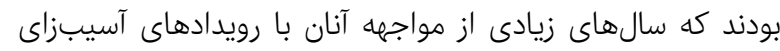

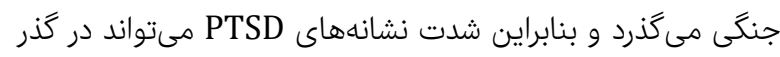

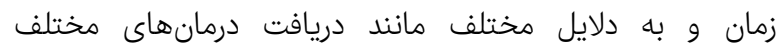

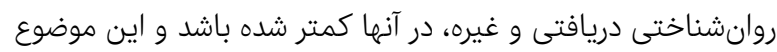

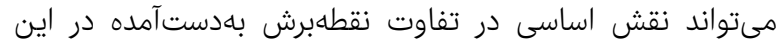
يُّوهش نسبت به نقطهبرش بررسى فوا و همكاران داشته باشد.

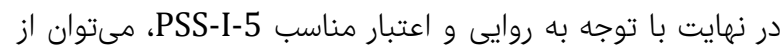

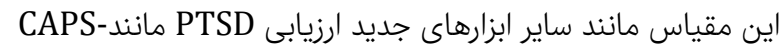

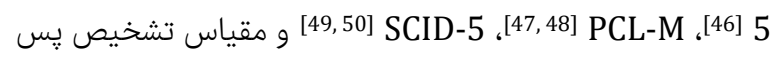

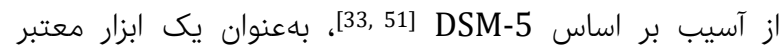

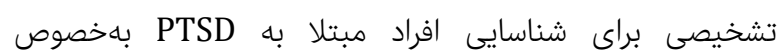

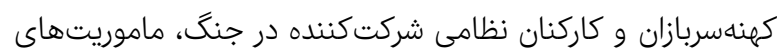
عملياتى و انتظامى، استفاده كرد. مهمترين محدوديتهاى يزّوهش حاضر، كمبود تعداد افراد نمونه،

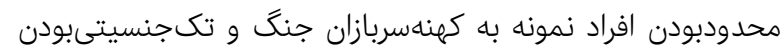

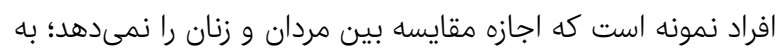

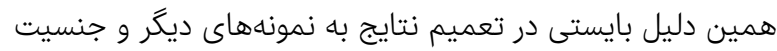

PSS- باهمنظور مقايسه ميانگينهائ وهاى افراد بيمار و سالم در مقياس

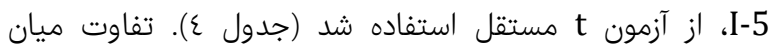

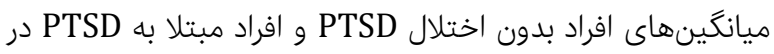
زيرمقياسها و نمره كل مقياس PSS-I-5 از نظر آمارى معنادار بود إديناس

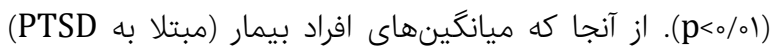

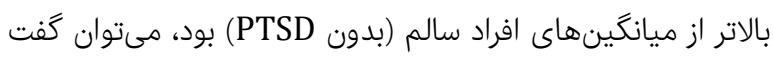
كه مقياس PSS-I-5 قابليت افتراق بين افراد بيمار و سالم را داشت.

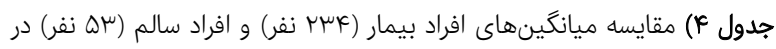

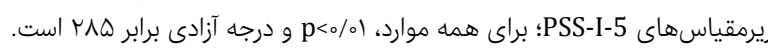

\begin{tabular}{|c|c|c|}
\hline مقدار t & ميانكين آمارى & زيرمقياسهاى PSS-I-5 \\
\hline \multirow{3}{*}{$-1 K / V \mu$} & & نشانههاى تجربه مجدد \\
\hline & $K / V Y \pm Y / \circ D$ & بدون اختلال \\
\hline & $10 /{ }^{\mu} \pm r / F F$ & با اختلال \\
\hline \multirow{3}{*}{$-\Lambda / \Lambda \varepsilon$} & & نشانههاى اجتنابى \\
\hline & $1 / 4 V \pm 1 / \circ \Delta$ & بدون اختلال \\
\hline & $\Psi / V \backslash \pm I / V V$ & با اختلال \\
\hline \multirow{3}{*}{$-|k / 9|$} & & تغييرات در شناخت و خلق \\
\hline & $8 / \mu^{\prime} \pm 1 / \wedge k$ & بدون اختلال \\
\hline & $\mid r / 9 ૬ \pm \Psi / \circ \Lambda$ & با اختلال \\
\hline \multirow{3}{*}{$-I r / \Lambda F$} & & برانكيختىى و واكنشيذيرى \\
\hline & $V / K q \pm r / r Q$ & بدون اختلال ب \\
\hline & $\mid r / Q \mu_{ \pm} \pm r / 9 \Delta$ & با اختلال \\
\hline \multirow{3}{*}{$-1 V / 9 \mu$} & & نمره كل \\
\hline & $19 / 91 \pm \psi / 9 \vee$ & بدون اختلال \\
\hline & $\mu / / q \mu \pm V / F \Lambda$ & با اختلال \\
\hline
\end{tabular}

بحث

با توجه به تغييرات بهوجودآمده در معيارهاى تشخيص PTSD در DSM-5

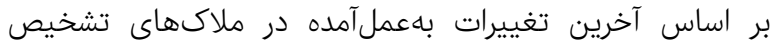

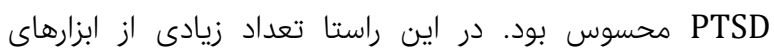

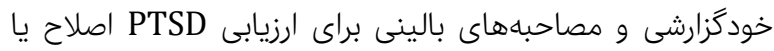

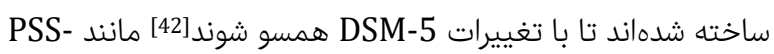

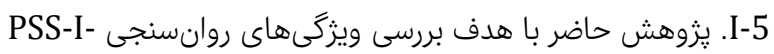

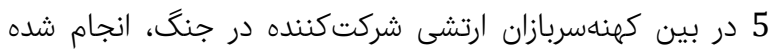

در اين يزوهش براى سنجش همسانى درونى بين سئوالهاى

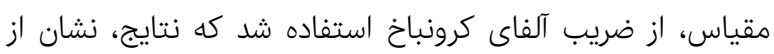

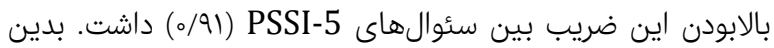

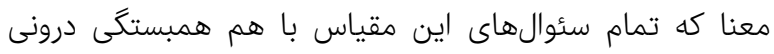

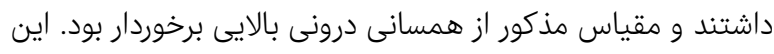

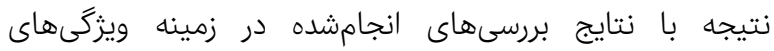
روانسنجى 33, 44,45] PSS-I-5 همسو است. نتايج مطالعه فوا و و

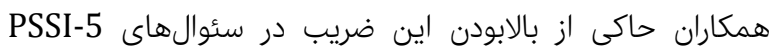

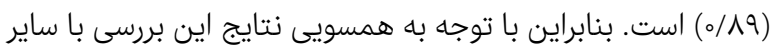

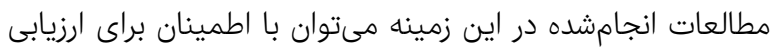


ويزگكىهاى روانسنجى مقياس/مصاحبه علايم اختلال استرس يس از آسيب بر اساس ... سץا 6- Perrin M, Vandeleur CL, Castelao E, Rothen S, Glaus J, Vollenweider $\mathrm{P}$, et al. Determinants of the development of post-traumatic stress disorder, in the general population. Soc Psychiatry Psychiatr Epidemiol. 2014;49(3):447-57.

7- Frans Ö, Rimmö PA, Åberg L, Fredrikson M. Trauma exposure and post-traumatic stress disorder in the general population. Acta Psychiatr Scand. 2005;111(4):291-9.

8- Rahnejat AM, Dabagi P, Rabiei M, Taghva A, Valipoor H, Donyavi $\mathrm{V}$, et al. Prevalence of post-traumatic stress disorder caused by war in veterans. Iran J War Pub Health. 2017;9(1):15-23. [Persian]

9- American Psychiatric Association. Diagnostic and statistical manual of mental. $4^{\text {th }}$ Edition. Washington: American Psychiatric Association; 2000.

10- Zungu LI. Prevalence of post-traumatic stress disorder in the South African mining industry and outcomes of liability claims submitted to Rand Mutual Assurance Company. Occup Health South Afr. 2013;19(2):22-6.

11- Ozer EJ, Best SR, Lipsey TL, Weiss DS. Predictors of posttraumatic stress disorder and symptoms in adults: A meta-analysis. Psychol Bull. 2003;129(1):52-73.

12- Wittchen HU, Gloster A, Beesdo K, Schönfeld S, Perkonigg A. Posttraumatic stress disorder: Diagnostic and epidemiological perspectives. CNS Spectr. 2009;14(1 Suppl 1):5-12.

13- Wittchen HU, Jacobi F. Size and burden of mental disorders in Europe--a critical review and appraisal of 27 studies. Eur Neuropsychopharmacol. 2005;15(4):357-76.

14- Kessler RC, Chiu WT, Demler O, Walters EE. Prevalence, severity, and comorbidity of 12-month DSM-IV disorders in the National Comorbidity Survey Replication. Arch Gen Psychiatry. 2005;62(6):617-27.

15- Alonso J, Angermeyer MC, Bernert S, Bruffaerts R, Brugha TS, Bryson H, et al. Prevalence of mental disorders in Europe: Results from the European Study of the Epidemiology of Mental Disorders (ESEMeD) project. Acta Psychiatr Scand Suppl. 2004;(420):21-7.

16-Alonso J, Angermeyer MC, Bernert S, Bruffaerts R, Brugha TS, Bryson $\mathrm{H}$, et al. Disability and quality of life impact of mental disorders in Europe: Results from the European Study of the Epidemiology of Mental Disorders (ESEMeD) project. Acta Psychiatr Scand Suppl. 2004;(420):38-46.

17- Alonso J, Angermeyer MC, Bernert S, Bruffaerts R, Brugha TS, Bryson $\mathrm{H}$, et al. 12-month comorbidity patterns and associated factors in Europe: Results from the European Study of the Epidemiology of Mental Disorders (ESEMeD) project. Acta Psychiatr Scand Suppl. 2004;(420):28-37.

18- Schneiderman AI, Braver ER, Kang HK. Understanding sequelae of injury mechanisms and mild traumatic brain injury incurred during the conflicts in Iraq and Afghanistan: Persistent postconcussive symptoms and posttraumatic stress disorder. Am J Epidemiol. 2008;167(12):1446-52.

19- Gates MA, Holowka DW, Vasterling JJ, Keane TM, Marx BP, Rosen RC. Posttraumatic stress disorder in veterans and military personnel: Epidemiology, screening, and case recognition. Psychol Serv. 2012;9(4):361-82.

20- Lehavot K, Katon JG, Chen JA, Fortney JC, Simpson TL. Post-traumatic stress disorder by gender and veteran status Am J Prev Med. 2018;54(1):e1-9.

21- Nichter B, Norman S, Haller M, Pietrzak RH. Psychological burden of PTSD, depression, and their comorbidity in the U.S. veteran population: Suicidality, functioning, and service utilization. J Affect Disord. 2019;256:633-40.

22- Dillon KH, Hale WJ, LoSavio ST, Wachen JS, Pruiksma KE, Yarvis JS, et al. Weekly changes in blame and PTSD among active-duty military personnel receiving cognitive processing therapy. Behav Ther. 2020;51(3):386-400.

23- Kudler H. Trauma and the Vietnam War Generation: Report of Findings from the National Vietnam Veterans Readjustment Study. J Nerv Ment Dis. 1991;179(10):644-5.

زن جانب احتياط را رعايت نمود.

ييشنهاد مىشود در يزوهشهاى آتى، PSS-I-5 در حجم بزرگى از جمعيت غيرنظاهى هر دو جنس كه تجاربى از مواجهاه با رويدادهاى آسيبزا دارند، هنجاريابى و كارآيى آن تعيين شود.

$$
\begin{aligned}
& \text { نتيجه } \\
& \text { مىتوان گفت كه PSS-I-5 از اعتبار همسانى، روايى همگرا، روايى } \\
& \text { واگرا، روايى افتراقى، نقطهبرش، حساسيت و ويزگگى مناسب برخوردار } \\
& \text { است؛ بنابراين مىتوان از PSS-I-5 در غربالگرى نيروهاى نظامى } \\
& \text { شركتكننده در جنگ و ماموريتهاى نظامى و انتظامى كه سابقه } \\
& \text { مواجه با رويداهاى آسيبزاى جنگى و نظامى را دارند، استفاده نمود. } \\
& \text { تشكر و قدردانى: بدينوسيله نويسندكان اين مقاله بر خود لازم مىدانند }
\end{aligned}
$$

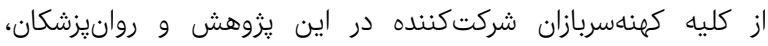

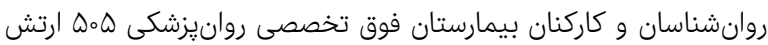

$$
\begin{aligned}
& \text { جمهورى اسلامى ايران تشكر و قدردانى كنند. } \\
& \text { تاييديه اخلاقى: اين مطالعه در معاونت يزوهش و فناورى دانشگًاه علوم } \\
& \text { يزشكى ارتش جمهورى اسلامى ايران با كد اخلاق بـ شماره }
\end{aligned}
$$

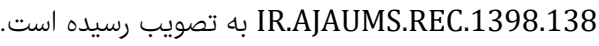

$$
\begin{aligned}
& \text { تعارض منافع: موردى بيان نشده است. }
\end{aligned}
$$

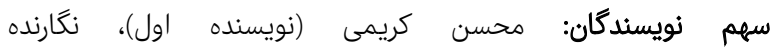

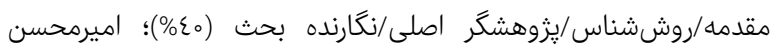

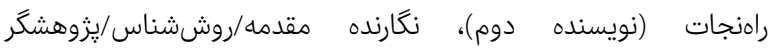

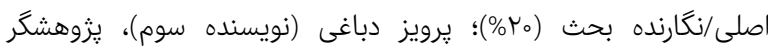
كمكى/تحليلكر آمارى (1\%)؛ ارسيا تقوا (نويسنده جهارم)، يزوهشگ

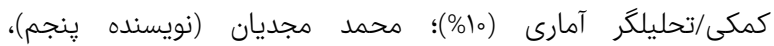
روششناس/يثوهشگر كمكى (10\%)؛ وحيد دنيوى (نويسنده ششم)،

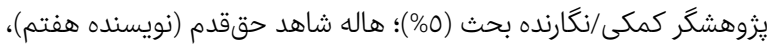

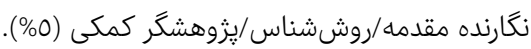

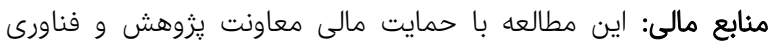
دانشگاه علوم يزشكى ارتش جمهورى اسلامى ايران انجام شده است.

1- Decker LR. Combat trauma: Treatment from a mystical/spiritual perspective. J Humanist Psychol. 2007;47(1):30-53.

2- Loignon A, Ouellet MC, Belleville G. A systematic review and meta-analysis on PTSD following TBI among military/veteran and civilian populations. J Head Trauma Rehabil. 2020;35(1):E21-35.

3- Lukaschek K, Kruse J, Emeny RT, Lacruz ME, von Eisenhart Rothe A, Ladwig KH. Lifetime traumatic experiences and their impact on PTSD: A general population study. Soc Psychiatry Psychiatr Epidemiol. 2013;48(4):525-32.

4- Amstadter AB, Aggen SH, Knudsen GP, ReichbornKjennerud T, Kendler KS. Potentially traumatic event exposure, posttraumatic stress disorder, and Axis I and II comorbidity in a population-based study of Norwegian young adults. Soc Psychiatry Psychiatr Epidemiol. 2013;48(2):21523.

5- Carlier IV, Voerman BE, Gersons BP. Intrusive traumatic recollections and comorbid posttraumatic stress disorder in depressed patients. Psychosom Med. 2000;62(1):26-32. 
US combat soldiers: A head-to-head comparison of DSM-5 versus DSM-IV-TR symptom criteria with the PTSD checklist. Lancet Psychiatry. 2014;1(4):269-77.

39- Blanchard EB, Jones-Alexander J, Buckley TC, Forneris CA. Psychometric properties of the PTSD Checklist (PCL). Behav Res Ther. 1996;34(8):669-73.

40- Morley CA, Kohrt BA. Impact of peer support on PTSD, hope, and functional impairment: a mixed-methods study of child soldiers in Nepal. J Aggress Maltreat Trauma. 2013;22(7):714-34.

41- Renner W, Salem I. Post-traumatic stress in asylum seekers and refugees from Chechnya, Afghanistan, and West Africa: Gender differences in symptomatology and coping. Int J Soc Psychiatry. 2009;55(2):99-108.

42- Weathers FW, Marx BP, Friedman MJ, Schnurr PP. Posttraumatic stress disorder in DSM-5: New criteria, new measures, and implications for assessment. Psychol Inj Law. 2014;7(2):93-107.

43- Firoozabadi A, Asgharnejad Farid AA, Mirzaei J, Shareh H. Normalization of clinician administered PTSD scale-version 1 (CAPS-5-1) for psychological effects due to war. Iran J Psychiatry Clin Psychol. 2010;15(4):334-42.

44- Roche L. An acceptance and commitment therapy-based intervention for PTSD following traumatic brain injury: A case study. Brain Inj. 2020;34(2):290-7.

45- Hakvoort L, de Jong S, van de Ree M, Kok T, Macfarlane C, de Haan $\mathrm{H}$. Music therapy to regulate arousal and attention in patients with substance use disorder and posttraumatic stress disorder: A feasibility study. J Music Ther. 2020;57(3):353-78.

46- Weathers FW, Bovin MJ, Lee DJ, Sloan DM, Schnurr PP, Kaloupek DG, et al. The Clinician-Administered PTSD Scale for DSM-5 (CAPS-5): Development and initial psychometric evaluation in military veterans. Psychol Assess. 2018;30(3):383-95.

47- Blevins CA, Weathers FW, Davis MT, Witte TK, Domino JL. The posttraumatic stress disorder checklist for DSM-5 (PCL5): Development and initial psychometric evaluation. J Trauma Stress. 2015;28(6):489-98.

48- Wortmann JH, Jordan AH, Weathers FW, Resick PA, Dondanville KA, Hall-Clark B, et al. Psychometric analysis of the PTSD Checklist-5 (PCL-5) among treatment-seeking military service members. Psychol Assess. 2016;28(11):1392-1403.

49- Shankman SA, Funkhouser CJ, Klein DN, Davila J, Lerner D, Hee D. Reliability and validity of severity dimensions of psychopathology assessed using the Structured Clinical Interview for DSM-5 (SCID). Int J Method Psychiatr Res. 2018;27(1):e1590.

50- Osório FL, Loureiro SR, Hallak JEC, Machado-de-Sousa JP, Ushirohira JM, Baes CV, et al. Clinical validity and intrarater and test-retest reliability of the Structured Clinical Interview for DSM-5-Clinician Version (SCID-5-CV). Psychiatry Clin Neurosci. 2019;73(12):754-60.

51- Alghamdi M, Hunt N. Psychometric properties of the Arabic Posttraumatic Diagnostic Scale for DSM-5 (A-PDS-5). Traumatology. 2020;26(1):109-16. 24- Prigerson HG, Maciejewski PK, Rosenheck RA. Population attributable fractions of psychiatric disorders and behavioral outcomes associated with combat exposure among US men. Am J Pub Health. 2002;92(1):59-63.

25- Hoge CW, Castro CA, Messer SC, McGurk D, Cotting DI, Koffman RL. Combat duty in Iraq and Afghanistan, mental health problems, and barriers to care. $\mathrm{N}$ Engl $\mathrm{J}$ Med. 2004;351(1):13-22.

26- Seal KH, Metzler TJ, Gima KS, Bertenthal D, Maguen S, Marmar CR. Trends and risk factors for mental health diagnoses among Iraq and Afghanistan veterans using Department of Veterans Affairs health care, 2002-2008. Am J Pub Health. 2009;99(9):1651-8.

27- Tanielian TL, Tanielian T, Jaycox L. Invisible wounds of war: Psychological and cognitive injuries, their consequences, and services to assist recovery. Santa Monica: Rand Corporation; 2008.

28- Vasterling JJ, Proctor SP, Friedman MJ, Hoge CW, Heeren T, King LA, et al. PTSD symptom increases in Iraq-deployed soldiers: Comparison with nondeployed soldiers and associations with baseline symptoms, deployment experiences, and postdeployment stress. J Trauma Stress. 2010;23(1):41-51.

29- Andrews B, Brewin CR, Philpott R, Stewart L. Delayedonset posttraumatic stress disorder: A systematic review of the evidence. Am J Psychiatry. 2007;164(9):1319-26.

30- Booth-Kewley S, Larson GE, Highfill-McRoy RM, Garland $\mathrm{CF}$, Gaskin TA. Correlates of posttraumatic stress disorder symptoms in Marines back from war. J Trauma Stress. 2010;23(1):69-77.

31- Foa EB, Riggs DS, Dancu CV, Rothbaum BO. Reliability and validity of a brief instrument for assessing post-traumatic stress disorder. J Trauma Stress. 1993;6:459-73.

32- Hooman HA, Ganji K, Omidifar A. The meta-analysis of the effectiveness of life skills training on mental health. J Dev Psychol Iran Psychol. 2013;10(37):39-50. [Persian]

33- Foa EB, McLean CP, Zang Y, Zhong J, Rauch S, Porter K, et al. Psychometric properties of the posttraumatic stress disorder symptom scale interview for DSM-5 (PSSI-5). Psychol Assess. 2016;28(10):1159-65.

34- Sadeghi M, Taghva A, Goudarzi N, Rah Nejat A. Validity and reliability of Persian version of "post-traumatic stress disorder scale" in war veterans. Iran J War Pub Health. 2016;8(4):243-9. [Persian]

35- Beck AT, Steer RA, Ball R, Ranieri WF. Comparison of Beck Depression Inventories-IA and-II in psychiatric outpatients. J Pers Assess. 1996;67(3):588-97.

36- Fata L, Birashk B, Atefvahid MK, Dabson KS. Meaning assignment structures/ schema, emotional states and cognitive processing of emotional information: Comparing two conceptual frameworks. Iran J Psychiatry Clin Psychol. 2005;11(3):312-26. [Persian]

37- Taqavi M, Najafi M, Kianersi F, Aqayan S. Comparing of alexithymia, defensive styles and state-trait anxiety among patients with generalized anxiety disorder major depression disorder and normal individuals. J Clin Psychol. 2013;5(2):67-76. [Persian]

38- Hoge CW, Riviere LA, Wilk JE, Herrell RK, Weathers FW. The prevalence of post-traumatic stress disorder (PTSD) in 